\title{
Roh Jahat yang dari pada Tuhan: Suatu Penelusuran Terhadap 1 Samuel 16:14-23
}

\author{
Madah \\ Institut Agama Kristen Negeri Toraja \\ madahpongelo@gmail.com
}

\begin{abstract}
An evil spirit from God is revealed in the Book of 1 Samuel 16: 14-23. The statement raises contradictions regarding the existence of a holy and true God in Christianity's outlook and outlook. In the context of the Old Testament the existence of a holy God is emphasized. Is it true that the existence of a holy God is the source of evil spirits? Can God be equated that He compromises with evil spirits in carrying out His plans? Related to this problem, the purpose of the research is to look for the meaning of evil spirits from God in 1 Samuel 16: 14-23. This writing uses a qualitative method with a kind of narrative approach to find the meaning of evil spirits from God in 1 Samuel 16: 14-23. The findings in this writing are that God used an evil spirit to punish Saul. God's judgment came to Saul through an evil spirit because of an act of rebellion against God. Furthermore, the presence of an evil spirit in Saul shows that God can use anything to carry out His plans. The evil spirit that was bothering Saul was by God's will. It means that the evil spirit is in God's control. The evil spirit from God in 1 Samuel 16: 14-23 is God not the source of evil spirits, but God wills and uses evil spirits to carry out His plans and His judgments for those who oppose His will.
\end{abstract}

Keywords: God, True, Holy, His Plan, Evil Spirits.

Abstrak-Roh jahat dari Tuhan dinyatakan dalam Kitab 1 Samuel 16:14-23. Pernyataan tersebut menimbulkan kontradiksi terkait keberadaan Allah yang kudus dan benar dalam penasiran dan pandangan iman Kristen. Dalam konteks Perjanjian Lama keberadaan Allah yang kudus sangat ditekankan. Benarkah keberadaan Tuhan yang kudus adalah sumber roh jahat? Dapatkah Allah disejajarkan bahwa Ia kompromi dengan roh jahat dalam menjalankan rencana-Nya? Terkait masalah tersebut maka tujuan penelitian adalah untuk mencari makna roh jahat dari pada Tuhan dalam Kitab 1 Samuel 16:14-23. Penulisan ini menggunakan metode kualitatif dengan jenis pendekatan narasi untuk menemukan makna roh jahat dari pada Tuhan dalam Kitab 1 Samuel 16:14-23. Temuan-temuan dalam penulisan ini adalah bahwa Tuhan memakai roh jahat untuk menghukum Saul. Penghukuman Allah datang kepada Saul melalui roh jahat karena tindakan pemberontakan kepada Allah. Selanjutnya bahwa hadirnya roh jahat pada diri Saul menunjukkan bahwa Allah dapat memakai apa saja untuk menjalankan rencana-Nya. Roh jahat yang mengganggu Saul adalah atas kehendak Allah. Maksudnya bahwa Roh jahat berada dalam kendali Allah. Roh jahat yang dari pada Tuhan dalam 1 Samuel 16:14-23 adalah Allah bukan sumber roh jahat, tetapi Allah menghendaki dan memakai roh jahat untuk menjalankan rencana-Nya dan penghukuman-Nya bagi yang melawan kehendak-Nya.

Kata Kunci: Allah, Benar, Kudus, Rencana-Nya, Roh jahat. 


$\begin{array}{llll}\text { Article History : } & \text { Received: 19-Mei-2020 } & \text { Revised: } & \text { Accepted: 29-Juni-2020 }\end{array}$

\section{Pendahuluan}

Konsep tentang roh jahat dari pada Tuhan dalam Kitab Samuel 16:14-23 menimbulkan kontradiksi dalam penafsiran. Tuhan sebagai sumber roh jahat sangat tidak sesuai. Dalam Perjanjian Lama, Keberadaan Allah yang kudus dan benar sangat jelas dinyatakan. Terkait keberadaan-Nya yang kudus dan benar maka Allah tidak mungkin sebagai sumber roh jahat.

Narasi 1 Samuel 16:14-23 mendeskripsikan keberadaan Saul adalah raja Israel yang terpilih berdasarkan undian dan diurapi untuk menjadi pemimpin bagi bangsa Israel. Dia sangat dipenuhi oleh roh Allah. Roh Tuhan tersebut meneyertai serta membimbing Saul sejak ia diurapi menjadi raja israel. ${ }^{1}$ Tetapi roh Allah yang dahulunya tinggal dalam diri Saul digantikan dengan roh jahat yang dari pada Tuhan. Roh jahat itu membuat Saul sangat tidak tenang dan merasa tidak nyaman. Saul telah ditolak olehTuhan menjadi pemimpin bagi bangsa Israel sehingga roh Tuhan meninggalkan dia dan kini diganggu Roh jahat. Hal ini membuat saul mulai gelisa ${ }^{2}$ dan mengalami depresi ${ }^{3}$ karena gangguan roh jahat. ${ }^{4}$ Saul mencari cara untuk mengusir roh jahat dari dirinya. Melalui nasehat hamba-hambanya saul menemukan seorang yang dapat menolongnya yaitu Daud. Daud memainkan kecapi bagi Saul sehingga Saul menjadi tenang. Dalam teks 1 Samuel 16: 14-23 dijelaskan bahwa permainan kecapi Daud membuat roh jahat undur dari pada Saul.

\section{Metode Penelitian}

Karena tulisan karia ilmiah ini adalah kajian narasi tentang roh jahat yang dari pada Tuhan, maka penulis akan menggunakan metode narasi biblika yakni penafsiaran Alkitab sebagai sumber utama. Penulisan narasi ini akan dibuat berdasarkan plot, adegan narasi, bagan, kiastik, percakapan-percakapan yang terjadi, karakter-karakter, atmosfir, sudut pandang narator terhadap setiap kegiaatan, kata-kata pengulangan. Setiap sub-sub tersebut akan disusun dalam bentuk deskripsi secara sistematis berdasarkan penulisan narasi untuk makna Roh jahat dari Tuhan.

1 Robert M. Paterson, Tafsir Alkitab Kontekstual-Oikumenis 1 \& 2 Samuel (Jakarta: Bpk Gunung Mulia, 2017), 144.

2 Robert M. Paterson, Tafsir Alkitab Kontekstual-Oikumenis 1 \& 2 Samuel (Jakarta: Bpk Gunung Mulia, 2017), 144.

3 W.S Lasor D.A Hubbard F.W Bush, Pengantar Perjanjian Lama 1 Taurat \& Sejarah (Jakarta: Gunung Mulia, 2011), 341.

${ }^{4}$ BUSH, PENGANTAR PERJANJIAN LAMA 1 TAURAT \& SEJARAH. 


\section{Hasil Dan Pembahasan}

Plot/Adegan Kitab 1 Samuel 16:14-23

\begin{tabular}{|l|l|l|}
\hline Plot & Adegan & Keterangan \\
\hline \multirow{4}{*}{$\begin{array}{l}\text { Awal 16:14-18; di istana } \\
\text { Saul }\end{array}$} & Ayat 14 & Saul diganggu roh jahat \\
\cline { 2 - 3 } & Ayat 15-16 & $\begin{array}{l}\text { hamba-hamba Saul } \\
\text { menasehati Saul }\end{array}$ \\
\cline { 2 - 3 } & Ayat 17 & $\begin{array}{l}\text { respon Saul terhadap nasehat } \\
\text { hamba-hambanya }\end{array}$ \\
\cline { 2 - 3 } $\begin{array}{l}\text { Tengah 16:19-20; di rumah } \\
\text { Isai }\end{array}$ & Ayat 18 & $\begin{array}{l}\text { Jawaban salah seorang hamba } \\
\text { kepada Saul }\end{array}$ \\
\cline { 2 - 3 } & Ayat 20 & $\begin{array}{l}\text { Saul mengirim pesan kepada } \\
\text { Isai }\end{array}$ \\
\hline \multirow{4}{*}{$\begin{array}{l}\text { Akhir 16:21-23; di istana } \\
\text { Saul }\end{array}$} & Ayat 21 & $\begin{array}{l}\text { Jawaban Isai terhadap pesan } \\
\text { Saul }\end{array}$ \\
\cline { 2 - 3 } & Ayat 22 & Daud dan Saul bertemu \\
& Ayat 23 & $\begin{array}{l}\text { Saul meminta Daud menjadi } \\
\text { pelayannya }\end{array}$ \\
\cline { 2 - 3 } & Roh jahat undur dari Saul \\
\hline
\end{tabular}

Berdasarkan pembagian plot di atas, maka bagian awal narasi pasal 16 dimulai dengan masuknya roh jahat ke dalam diri Saul yang membuat Saul tidak tenang. adanya gangguan roh jahat tersebut, sehingga hamba-hamba Saul menasehati Saul untuk mencari orang yang dapat menolongnya. Adegan 1 (ayat 14-16) ketika roh jahat masuk ke dalam diri Saul, hamba-hambanya melihat itu dan menasihati Saul untuk mencari orang yang pandai bermain kecapi untuk menenangkan Saul. Hal itu dilakukan oleh hamba-hamba saul sebagai rasa simpati mereka kepada tuannya. Adegan 2 (ayat 17) Saul mendengarkan dan menerima nasehat hamba-hambanya, dan memerintahkan hambanya untuk mencari orang yang pandai bermain kecapi dan menjadi pelayannya. Adegan 3 (ayat 18) seorang dari hamba Saul merespon perintah tuannya dan menginformasikan bahwa ia telah melihat seorang yang pandai dalam bermain kecapi yaitu anak Isai orang Betlehem.

Bagian tengah dari narasi pasal 16 menceritakan bahwa Saul langsung mengirim suruhan kepada Isai lalu Isai merespon pesan Saul melalui Daud anaknya. Adegan 4 (ayat 19) saul mengirim pesan kepada Isai untuk mengirimkan Daud anaknya kepadanya. Adegan 5 (ayat 20) Isai merespon dan membalas pesan Saul dengan mengirimkan Daud anaknya dengan seekor keledai yang dimuati roti dan sekirbat anggur kepada Saul.

Bagian akhir dari pasal 16 diakhiri dengan perjumpaan Saul dan Daud serta kemampuan Daud memainkan kecapi dan mengusir roh jahat pada diri Saul. Adegan 6 (ayat 21-22) Daud sampai kepada Saul dan melaksanakan tugasnya sebagai pelayan dengan penuh tangguang jawab dan Saul sangat mengasihinya. Saul mengirim pesan 
kepada Isai untuk tetap membiarkan Daud anaknya tetap menjadi pelayannya. Adegan 7 (ayat 23)setiap kali roh jahat mennganggu saul, Daud memainkan kecapi dan membuat saul merasa tenang dan roh jahat itu undur dari padanya.

\section{Bagan}

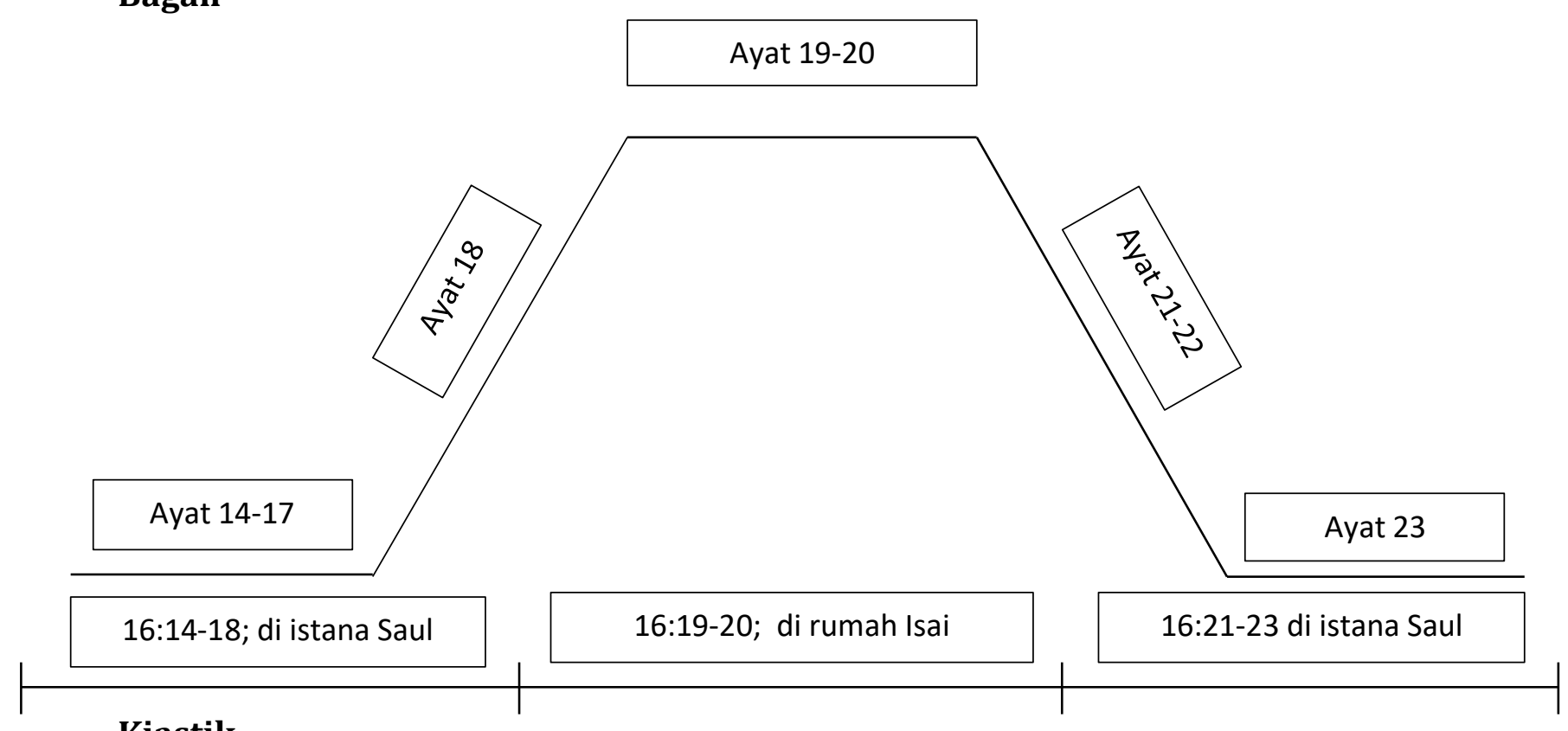

\section{Kiastik}

a. Roh jahat menggangu Saul (ayat 14)

b. Percakapan antara Saul dan hamba-hambanya(ayat 15-18)

c. Saul mengirim pesan kepada Isai (ayat 19)

d. Respon Isai kepada Saul (ayat 20)

e. Daud bertemu Saul dan menjadi pelayan Saul(ayat 21)

f. Saul ingin agar Daud tetap menjadi pelayan Saul (ayat 22)

g. Roh jahat undur dari pada Saul (ayat 23)

\section{Penulisan Narasi Pasal 16}

\begin{tabular}{|l|l|l|}
\hline Oknum & Ayat & Keterangan \\
\hline Narator & Ayat 14 & $\begin{array}{l}\text { 16:14 Roh Tuhan meninggalkan saul dan sekarang } \\
\text { Saul diganggu oleh roh jahat yang dari pada Tuhan }\end{array}$ \\
\hline Hamba-hamba & Ayat 15-16 & $\begin{array}{l}16: 15-16 \text { hamba-hamba Saul mengetahui bahwa } \\
\text { roh jahat dari Tuhan mengganggu tuannya lalu } \\
\text { mereka mensihati Saul agar mencari seorang yang } \\
\text { pandai bermain kecapi untuk membuat Saul } \\
\text { menjadi tenang dan merasa nyaman. }\end{array}$ \\
\hline Saul & Ayat 17 & $\begin{array}{l}16: 17 \text { Saul memerintahkan hamba-hambanya } \\
\text { untuk mencarikan seorang yang pandai bermain } \\
\text { kecapi baginya }\end{array}$ \\
\hline Hamba & Ayat 18 & \begin{tabular}{l}
$16: 18$ salah satu hamba Saul menginformasikan \\
\hline
\end{tabular} \\
\hline
\end{tabular}




\begin{tabular}{|l|l|l|}
\hline & & $\begin{array}{l}\text { bagi Saul tentang Anak Isai, yaitu Daud yang gagah } \\
\text { perkasa dan ia pandai bermain kecapi }\end{array}$ \\
\hline Saul & Ayat 19 & $\begin{array}{l}16: 19 \text { Saul menirim pesan kepad Isai untuk } \\
\text { menyuruh anak Daud datang kepad Saul }\end{array}$ \\
\hline Narator & Ayat 20-21 & $\begin{array}{l}16: 20 \text { lalu Isai mengirim anaknya Daud kepada } \\
\text { Saul sesuai dengan perintah Saul } \\
16: 21 \text { Daud bertemu dengan Saul dan menjadi } \\
\text { pelayannya dan Saul sangatmengasihinya. }\end{array}$ \\
\hline Saul & Ayat 22 & $\begin{array}{l}16: 22 \text { Saul meminta kepada Isai agar Daud tetap } \\
\text { menjadi pelayannya }\end{array}$ \\
\hline Narator & Ayat 23 & $\begin{array}{l}16: 23 \text { ketika daud memainkan kecapi, roh jahat } \\
\text { yang dari pada Tuhan undur daripad Saul dan ia } \\
\text { menjadi tenang }\end{array}$ \\
\hline
\end{tabular}

Dari ayat-ayat yang ada, menjelaskan bahwa Saul memilih Daud untuk menjadikan ia sebagai pelayannya dan saul sangat mengasihi Daud. Daud mampu mengusir roh jahat dari pada Saul dengan memainkan kecapi dan itu semua melalui penyertaan Tuhan kepada Daud.

\section{Percakapan}

Dalam pasal 16 terdapat Saul, Daud, Isai, hamba-hamba, roh jahat, dan Tuhan. Dalam pasal 16 Saul adalah pusat percakapan karakter. Percakapan dalam pasal 16 terjadi dialog antara Saul dan hamba-hamba, dialog antara Saul dan Isai, dan dialog antara Saul dan Daud. Namun dalam setiap dialog yang ada selalu menghasilkan respon dalam bentuk perkataan, tindakan, dan sikap yang paling sering ditunjukkan oleh Saul.

\begin{tabular}{|l|l|}
\hline Ayat 14-16( hamba-hamba ) & \\
\hline & Ayat 17 (saul) \\
\hline Ayat 18 (hamba ) & \\
\hline & Ayat 19 (saul) \\
\hline Ayat 10 (isai ) & \\
\hline & Ayat 21a (Daud) \\
\hline Ayat t 21b (saul) & \\
\hline & Ayat 22 (Saul) \\
\hline Ayat 23 (Daud) & \\
\hline
\end{tabular}

Percakapan pertama (ayat 14-17) yakni nasehat dari hamba-hamba Saul. dalam suatu percakapan hamba-hamba Saul berkata "ketahuilah, roh jahat yang dari pada Allah menggangu engkau, baiklah tuanku menitahkan hamba-hambamu yang di depanmu ini mencari seorang yang pandai main kecapi , dan Apabila roh jahat yang dari 
pada Allah itu hinggap padamu, haruslah ia main kecapi, maka engkau merasa nyaman. Dari nasehat hamba-hamba Saul tersebut maka Saul memberikan Jawaban atas nasehatnasehat hamba-hambanya (ayat !7): "Carilah bagiku seorang yang dapat main kecapi dengan baik, dan bawalah dia kepadaku".

Percakapan kedua (ayat 18-19a) yakni salah seorang hamba saul memberitahukannya tentang Daud bahwa ia telah melihat salah seorang anak laki-laki Isai, orang Betlehem itu, yang pandai main kecapi. Ia seorang pahlawan yang gagah perkasa, seorang prajurit, yang pandai bicara, elok perawakannya; dan TUHAN menyertai dia". Dari pernyataan hamba Saul tersebut maka respon Saul bukan berupa perkataan melainkan tindakan dan mengirimkan pesan kepada Isai.

Percakapan ketiga (ayat 19b-20) yakni Pesan Saul kepada Isai agar mengirimkan anak Isai yakni Daud, yang ada pada kambing domba itu". Lalu Isai merespon pesan Saul bukan dengan perkataan tetapi melalui tindakan dengan mengambil seekor keledai yang dimuati roti, sekirbat anggur, dan seekor anak kambing, maka di kirimkannyalah itu kepada Saul dengan perantaraan Daud, anaknya.

Percakapan keempat (ayat 21-22) khususnya dalam ayat 21a menunjukkan sikap dan tindakan Daud sebagai pelayan yang baik bagi Saul. Jawaban saul yang pertama dalam ayat 21b-22 berupa tindakan dengan cara mengasihi Daud dan mempercayakan Daud sebagai pembawa senjatanya. Jawaban Saul yang kedua ialah dengan mengirimkan pesan kepada Isai bahwa biarkanlah Daud tetap menjadi pelayanku sebab aku suka padanya".

Percakapan kelima (23) di mana Daud menjadi pelayan yang baik bagi Saul. Setiap kali roh jahat yang dari pada Tuhan hinggap pada Saul, maka Daud mengambil kecapi dan memainkannya sehingga Saul menjadi tenang dan nyaman. Pembicaraan keempat adalah hasil dari apa yang telah Daud kerjakan sebagai pelayan yang baik bagi saul dan yang memainkan kecapi bagi saul. Allah turut mengambil bahagian dalam permainan Daud

\section{Karakter Dalam Pasal 16}

Saul (Ayat 14, 17 dan 21b-22)

Saul adalah raja di israel. Ia tinggal di istananya bersama hamba-hambanya. Ia dilayani dengan baik oleh hamba-hambanya. Saul pada awalnya sangat di penuhi oleh Roh Tuhan. Akan tetapi pada suatu hari Saul diganggu oleh roh jahat yang dari pada Tuhan dalam ayat 14. Pada saat ia diganggu roh jahat dan hamba-hambanya melihat hal itu dan menasihati Saul untuk mencari seorang yang pandai memaikan kecapi agar ia tenang (ayat 16). Saul menitakan hambanya untuk mencarikan seorang yang pandai memainkan kecapi dan untuk menjadi pelayan baginya (ayat 17). Hambanya memberitahukan tentang Daud kepadanya. Dan sikap dan tindakan Daud membuat Saul sangat mengasihinya. Daud diangkat menjadi pelayannya dan dipercayakan sebagai pembawa senjatanya. Kesenangan Saul kepada Daud lebih nampak lagi ketika saul meminta kepada Isai ayah Daud agar Daud tetap menjadi pelayannya.

\section{Hamba-hamba (15,16 dan 18)}


Hamba-hamba adalah orang-orang yang bersama Saul di istananya. Hambahamba saul sangat peduli kepada tuannya dan melayani saul dengan baik. Kepedulian mereka sangat nampak ketika Saul di ganggu roh jahat. Mereka menasihati tuannya untuk mencari seseorang yang bisa menolongnya dan membuatnya tenang dengan cara memainkan kecapi baginya. Hamba-hamba Saul sangat taat kepadanya. Hal ini jelas ketika Saul memerintahkan mereka untuk mencari seorang yang pandai. Tindakan perhatian hamba tersebut spontan menginformasikan tentang Daud kepadanya (ayat 18). Tidak ada penolakan dari hambanya. Hal ini membuktikan bahwa hamba-hambanya sangat peduli dan setia kepada Saul.

\section{Isai (ayat 20)}

Isai adalah seorang yang berasal dari Betlehem. Salah satu hamba saul memberitahukan bahwa ia mempunyai seorang anak yang pandai memainkan kecapi (ayat 18b). Tidak ada penjelasan yang rinci tentang kehidupan keluarga Isai. Tetapi sepertinya Isai bekerja sebagai petani dan juga peternak, dan berasal dari keluarga yang sederhana. Hal ini terlihat pada saat Isai merespon pesan Saul, ia mengambil seekor keledai dan dimuati roti dan sekirbat anggur dan seekor anak kambing dan dikirimnyalah itu kepada Saul. Hal ini memberikan sedikit gambaran tentang kehidupan keluarga Isai (ayat 20).

\section{Daud (ayat 21-23)}

Daud adalah anak Isai, ia berasal dari betlehem. Ia adalah seorang pahlawan yang gagah perkasa, seorang prajurit yang pandai bicara, dan elok perawakannya. Daud pandai dalam memainkan kecapi dan Tuhan menyertai dia. Daud memiliki sikap yang baik sehingga saul memuji dia serta sangat mengasihinya. Daud bertanggung jawab dalam melakukan tugasnya sebagi pelayan bagi saul. Hal ini terbukti saat Saul meminta kepada Isai agar daud tetap menjadi pelayannya (ayat 22b).

\section{Roh Tuhan (ayat 14a)}

Pada awalnya Roh Tuhan menguasai hati Saul dan sepertinya ia tenang. Tidak ada permasalahan yang timbul.

\section{Roh jahat (ayat $14 b$ dan 23)}

Roh jahat merasuki saul, dan hal ini sangat membuat dia terganggu dan tidak nyaman. Kehadiran roh jahat dalam diri Saul membuat ia merasa tidak tenang. Hambhambanya yang melihat hal itu menasihati saul untuk mencari seorang yang pandai dalam memainkan kecapi. Hamba-hamba Saul mencari orang yang bisa menolongnya. Roh jahat yang ada dalam diri saul undur pada saat Daud memainkan kecapi. Sepertinya roh jahat tidak suka pada permainan kecapi Daud, sehingga setiap kali Daud memainkan kecapi roh jahat undur dari pada Saul (ayat 23). 


\section{Atmosfir}

Dalam pasal 16 situasi yang diinformasikan awalnya ada sebuah permasalahan yang terjadi khususnya bagi Saul sebagai sumber timbulnya masalah. Masalah yang terjadi adalah ia diganggu roh jahat. Melalui nasehat hamba-hambanya, Saul mencari seorang yang dapat menolongnya dengan cara memainkan kecapi baginya. Saul memilih Daud untuk menjadi pelayannya dan memainkan kecapi baginya. Daud berhasil menjadi pelayan yang baik bagi Saul (ayat21-22) dan dengan memainkan kecapi roh jahat itu undur dari pada Saul(ayat 23).

\section{Narator}

Dalam menyusun narasi pasal 3, nampaknya narator berada di tiga tempat, yakni: di istana Saul ketika Saul diganggu roh jahat (ayat 14), di rumah isai (ayat 20), dan kembali di istana Saul, dimana Daud bertemu Saul dan ia menjadi pelayannya. Narator sangat mengetahui semua tindakan yang dilakukan Saul, hamba-hamba Saul, Isai, dan juga Daud.

Sepertinya narator dalam plot ini, selalu hadir dan menegetahui semua percakapan yang terjadi dalam kisah ini. Saat saul diganggu roh jahat hamba-hambanya tahu hal tersebut, sepertinya narator pun hadir disana menyaksikan secara seksama. Nampaknya, narator juga hadir saat saul menyampaikan pesan pertama kepada Isai. saat isai mengirim seekor keledai yang dimuati roti dan sekirbat anggur dan juga seekor anak kambing dan dikirimkannyalah itu kepada saul melalui Daud, nampaknya narator juga hadir. Saat Daud terpilih menjadi pelayan Saul, nampaknya narator hadir dan menyaksikan secara seksama hingga saat Daud memainkan kecapi sehingga membuat roh jahat undur dari pada saul.

Narator juga mengetahui seluruh percakapan-percakapan yang ada, baik percakapan antara Saul dan hamba-hambanya (ayat 14-18), percakapan antara Saul dan Isai, (ayat 19b-20 dan 22) juga percakapan Saul dan Daud (ayat 21 dan 23).

\section{Sudut Pandang Narator}

Dalam pasal 16 narator lebih terfokus pada undurnya roh jahat dari pada Saul. Hal inilah yang diinginkan Saul dan juga hamba-hambanya agar saul bisa merasa nyaman dan tenang.

Dalam pasal 16, narator lebih terfokus kepada hasil yang di peroleh dari setiap tindakan yang di lakukan mulai dari tindakan Saul, dan tindakan hamba-hambanya. Namun fokus dari tindakan itu ialah Saul. Hamba-hamba Saul ingin agar Saul mendapat pertolongan melalui permainan kecapi Daud agar Saul dapat tenang (ayat 15-18). Daud ingin menjadi pelayan dan memainkan kecapi bagi Saul (ayat 21). Dan Saul juga ingin Daud tetap menjadi pelayannya(ayat 22).

Perhatian narator terfukus pada Saul dan hamba-hambanya yang terjadi di istana Saul, percakapan antara Saul dan Isai di rumah isai, dan juga percakapan antara Daud dan Saul di istana, dan semuanya berakhir dengan menghasilkan tindakan dan suatu kesimpulan. 


\section{Kata-Kata Kunci Dan Pengulangan}

1. Diganggu/mengganggu. Kata ini muncul sebanyak dua kali dalam pasal 16 . Kata ini berkaitan dengan roh jahat yang selalu menggangu Saul dan membuat Saul tidak tenang. Saul merasa tidak nyaman akan gangguan roh jahat padanya sehingga dia mencari orang yang padai memainkan kecapi untuk menenangkan hatinya.

2. Main kecapi. Kata ini muncul sebayak lima kali dalam pasal 16. (ayat $16,17,18,23$ ). Hamba-hamba saul menasihati saul untuk mencari orang yang pandai main kecapi agar Saul menjadi tenang. Daud terpilih untuk memainkan kecapi bagi saul, dan roh jahat yang ada pada Saul undur dan saul menjadi nyaman.

3. Pandai. Kata ini muncul sebanyak tiga kali (ayat 16,18). Kata ini menjelaskan bahwa Daud adalah seorang yang pandai memainkan kecapi. kata ini menunjukkan kepribadian Daud yang dijelaskan oleh seorang Hamba.

4. Nyaman. Kata ini muncul sebanyak dua kali (ayat 16, 23) pada awalnya roh jahat hinggap pada Saul dan membuat Saul merasa tidak nyaman. Saul mencari sesorang yang pandai main kecapi. Daud terpilih menjadi pelayan Saul dan memainkan kecapi bagi saul sehingga Roh jahat itu tidak hinggap lagi pada Saul.

5. Pelayan. Kata ini muncul sebanyak dua kali dalam pasal 16 (ayat 21,22) kata ini menunjuk kepada tugas Daud sebagi pelayan bagi Saul. Daud dipilih saul menjadi pelayannya, dan saul sangat mengasihinya, saul ingin Daud tetap menjadi pelayannya.

6. Saul, Hamba-hamba, Isai, Daud, Roh Tuhan, Roh jahat, semua ini adalah nama tokoh yang disebut dalam pasal 16. Nama saul muncul sebanyak sepuluh kali (ayat 14, 15, $17,19,21,22,23$ ). Nama hamba-hamba muncul sebanyak empat kali (ayat 15, 16, 17,18 ). Nama Isai muncul sebanyak tiga kali (ayat 18, 19, 20). Nama Daud muncul sebanyak lima kali (ayat 19, 20,21,22,23). Roh Tuhan muncul sebanyak satu kali (ayat 14). Roh Jahat muncul sebanyak empat kali (ayat 14, 15, 16, 23).

\section{Konteks Roh Jahat Yang Dari Pada Tuhan Dalam 1 Samuel 16:14}

Konteks roh jahat dalam 1 samuel 16:14-23, didahului dengan Daud diurapi menjadi raja dalam pasal 16:1-13. Dalam pasal 16:1-13,menginformasikan bahwa Tuhan berfirman kepada Samuel untuk mempersembahkan korban bakaran bagi Tuhan. Dalam upacara tersebut Samuel mengundang Isai ke upacara pengorbanan itu. Samuel melakukan apa yang difirmankan Tuhan kepadanya. Kemudian Samuel menguduskan Isai dan anak-anaknya. Isai memanggil anak-anaknya lewat di depan Samuel tetapi tidak seorangpun yang disebutkan Tuhan. Samuel bertanya kepada Isai, inikah anakmu semuanya? Isai menjawab masih tinggal yang bungsu menggembalakan kambing domba. Samuel berkata kepada isai suruhlah dia kemari. Maka disuruhnyalah dia menjemputnya. Setelah ia datang berfirmanlah Tuhan kepada Samuel untuk mengurapinya. Lalu Samuel mengurapi Daud dan sejak saat itu Roh Tuhan menyertai dia sampai seterusnya.

Dalam pasal 15:1-35 menjelaskan tentang Saul ditolak menjadi raja karena ia 
melanggar apa yang diperintahkan Tuhan kepadanya. saul diperintahkan untuk mengalahkan orang amalek, serta menumpas habis segala segala yang ada padanya. Laki-laki dan perempuan, kanak-kanak, dan anak-anak menyusu, segala hewan milik mereka harus ditumpaskan. Tetapi Saul menyelamatkan Agag raja orang Amalek dan semua kambing domba yang ia miliki. Perbuatan Saul tersebut, maka menyesallah Tuhan karena Saul melanggar apa yang Tuhan perintahkan. Akibatnya Tuhan pun menolaknya sebagai raja.

Pasal 17:1-58 menginforamasikan bagaimana Goliat menantang orang israel dan Daud mengalahkannya. Orang Filistin mengumpulkan tentaranya, begitupun Saul mengumpulkan tentara orang israel. Ada seorang pendekar dari tentara orang Filistin, namanyax Goliat. Tingginya enam hasta sejengkal, ia menggunakan ketopong tembaga di kepalanya dan ia menggunakan baju Zirah yang beratnya lima ribu sykal tembaga. Dia memakai penutup kaki dari tembaga dan di bahunya ia memanggul lembing tembaga gagang tombaknya seperti pesah tukang tenun dan mata tombaknya itu enam ratus sykal perak beratnya. Dan aeorang pembawa perisai berjalan di depannya (ayat 4-7). Orang filistim mengecam orang israel. Mendengar perkataan orang filistin, Saul dan orang israel menjadi cemas dan sangat ketakutan. Tiga anak Isai ikut bersama-sam dengan Saul. Lalu isai memanggil Daud dan menyuruhnya untuk melihat keadaan saudarnya dengan membawa ganndum seefa dan sepuluh roti. Dan jugaDaud membawa sepuluh keju untuk kepala pasukan seribu. Dan setelah Daud kembali ia harus membawa suatu tanda dari saudara-saudaranya. Daud melakukan apa yang di perintahkan ayahnya. Setibanya dia di medan pertempuran ia mencari kakaknya lalu orang filistin mengucapkan ancaman mereka lagi dan Daud mendengarnya dan ia menghadap kepada Saul untuk melawan orang filistin tetapi Saul meremehkannya dan menganggap Daud tidak akan mampu melawan orang filistin. Tetapi Daud berkata Tuhan akan melepaskan aku dari tangan orang filistin. Saul berkata kepada Daud pergilah Tuhan meyertai engkau (ayat 37-38). Lalu Daud memanggil tongkatnya dan ia mengambil lima batu licin dari sungai dan ia memegang umbannya. Orang Filistin meremehkan Daud, tetapi Daud berkata engkau mendatangi aku dengan tombak tetapi aku mendatingi engkau atas nama Tuhan alam semesta(ayat 40-45). Ketika orang Filistin bergerak maka Daud mengambil sebuah batu diumbanyalah maka kena dahi orang Filistin itu dan tertanam dalam dahinya dan ia jatuh dengan muka ketan. Daud mengalahkan orang Filstin itu. Segenap orang israel bersorak dan mengejar orang Filistin.

Pasal 18:1-5 menginformasikan bahwa Daud dan Yonatan anak Saul bersahabat. Pasal 18:6-30, meginformasikan tentang kebencian Saul kepada Daud. Saul membenci Daud karena Daud selalu berhasil dalam peperangan. Pada saat itu roh jahat berkuasa atas saul. Daud memainkan kecapi seperti biasanya, Saul melemparkan Tombaknya Tuhan meyertai Daud, sedang Ia telah undur daripada Saul.

Untuk menjelaskan megenai roh jahat yang dari pada Tuhan, maka perlu dilakukan analisa terhadap pernyataan itu. Dalam pasal 16: 14 dikatakan bahwa "tetapi Roh Tuhan telah mundur dari pada Saul, dan sekarang ia diganggu oleh roh jahat yang dari pada Tuhan" dapat di terjemahkan kedalam beberapa versi yaitu: NIV: Now the Spirit of the LORD had departed from Saul and an evil Spirit from the LORD tormented him. ASV: Now the Spirit of the LORD departed from Saul, and harmful Spirit from the LORD tormented him. KJV: but the Spirit of the LORD departed from Saul, and an evil 
spirit from the LORD troubled him. FAYH: Roh tuhan telah meninggalkan Saul dan Tuhan membiarkan roh jahat mengganggu Saul sehingga jiwanya tertekan dan ia selalu ketakutan. BIS: Adapun Saul telah di tinggalkan oleh Roh Tuhan, dan kini ia di siksa oleh roh jahat di utus TUHAN. TL: Maka Roh Tuhan pun undurlah dari pada Saul dan seorang syaitan dari pada Tuhan mengejutkan dia TB :tetapi roh Tuhan telah undur dari pada Saul,dan sekarang ia diganggu oleh roh jahat yang dari pada Tuhan

Dari beberapa penjelasan terjemahan di atas, muncul beberapa perbedaan anataraversi yang berbeda. Versi NIV, KJV, TB menyatakan versi yang sama dimulai dengan Roh Tuhan meninggalkan atau undur dari Saul dan roh jahat yang dari pada Tuhan mengganggu atau menyiksa dia. Versi ASV menyatakan sekarang Roh Tuhan meninggalkan Saul dan roh berbahaya dari Tuhan menyiksa dia. versi BIS menyatakan ia disiksa roh jahat yang diutus Tuhan dan Versi TL menyatakan ia diganggu seorang syatan dari pada Tuhan. Berbeda dengan Versi FAYH menyatakan bahwa Tuhan membiarkan roh jahat mengganggu Saul sehingga jiwanya tertekan dan ia selalu ketakutan. Versi ini tidak mengatakan bahwa roh jahat itu berasal dari Tuhan tetapi atas seizin Tuhan roh jahat menganggu Saul.

Roh Tuhan mengejar Daud (ayat 13), yang telah pergi dari Saul. Sebelumnya roh Allah ada pada diri Saul dan menguasai Saul sehingga ia dapat memikul tugasnya sebagai raja Israel $(10: 10 ; 11: 6,10: 6)$. Kini Roh Allah beralih dari Saul kepada Daud. Perginya "roh Tuhan" kepada orang baru yakni Daud, berarti pemindahan "Pertolongan ilahi" dari Saul ke Daud, yang di Timur Dekat kuno dapat berubah dari dinasti ke dinasti, atau dari satu cabang dari sebuah rumah yang berkuasa ke rumah yang lain. Adapun Saul, sebagai hasil perginya roh Allah darinya, ia mulai diteror oleh jenis roh jahat dari Tuhan.5

\section{Roh Jahat dari Tuhan}

Ungkapan roh Jahat dari Tuhan memberi kesan bahwa roh Allah kadang-kadang bisa jahat. Berbagai saran telah diajukan untuk menyelesaikan masalah teologis ini. Keil dan Delitzsch membedakan antara roh jahat dari Tuhan, yang merupakan setan yang dikirim oleh Tuhan, dan Roh Tuhan, yang merupakan roh dari Allah yang kudus. Menurut Vriezen, fakta bahwa tidak hanya yang baik tetapi juga yang jahat berasal dari Yahweh menunjukkan bahwa ia juga memegang otoritas absolut atas kejahatan itu. 6

Eichrodt juga berpendapat bahwa roh jahat dari Tuhan adalah kekuatan spiritual di bawah kedaulatan Allah. Karenanya tidak sama dengan roh jahat, berbeda dengan roh yang baik, dalam dualisme kafir. McCarter menerima bahwa roh jahat adalah dari Tuhan dan menjelaskan bahwa bahkan ia memainkan bagiannya dalam mengerjakan rencana ilahi. Klein dan R. P. Gordon juga berpendapat bahwa PL cenderung memakai hal baik dan jahat di dalam kedaulatan Tuhan untuk menajalakan rencana dan penghukumanNya. seperti Ul. 13: 2-4; Amos 3: 6; 2 Sam. 24: 1; 1 Chr. 21: 1; Judg. 9:23; 1 Kg. 22: 19-22; Ayub 2:10.7

${ }^{5}$ David Tsumura, The New International Commentary on the Old Testament: The First Book of Samuel (Grand Rapids, MI: Eerdmans Publishing Co, 2007),426.

6Ibid., 426.

${ }^{7}$ Ibid. 
Namun, ini bukan masalah teologis seperti masalah tata bahasa. Terjemahan roh jahat dari Tuhan tidak cukup untuk bahasa Ibrani asli. Di sini disarankan bahwa frasa רוּסַ־רָעָה ruah raah, yang biasanya diterjemahkan sebagai roh jahat, harus diambil sebagai rantai konstruk, "roh kejahatan (atau bencana), karena רָעָ raah tidak terdapat kata sifat dalam rûah hārā'āh (16:23) dan רוּח יהוה רָעָה rûah YHWH rā'āh (19: 9). Ini mungkin didukung oleh fakta bahwa kata benda ำ rûah diikuti oleh kata benda lain 128 kali, dibandingkan dengan sekitar 20 kali ketika dimodifikasi oleh kata sifat Jadi, rûah hārā'āh dan רוּח יהוה רָעָה rûah YHWH rā'āh lebih baik diterjemahkan sebagai roh yang melahirkan bencana dan roh Tuhan yang membawa bencana, menganggap רָעָּ raah sebagai genitif objektif (genetika dari efek).8 Jadi, maksud pernyataan roh jahat dari pada Tuhan dapat ditafsirkan bahwa bentuk penghukman Allah bagi Saul yakni roh yang membawa bencana bagi Saul.

Sekarang roh jahat tiba dan seolah-olah bergegas masuk ke dalam hati Saul (McCarter) dan mulai menerornya. Hoftijzer dengan tepat menjelaskan bahwa situasi ini bukan hanya keadaan ketakutan tetapi sangat menyiksa Saul. Roh ini adalah penghukuman berasal dari Tuhan dan karenanya akan memainkan perannya dalam mengerjakan rencana ilahi.9

\section{Implikasi Teologis}

\section{Allah Memakai Segala Sesuatu Untuk Melaksanakan Rencananya}

Allah mengendalikan segala sesuatu untuk kebajikan sesuai dengan rencana-Nya untuk membuat hamba-hamba-Nya lebih baik.10 Allah mengendalikan dan memakai roh jahat untuk menghukum Saul atas apa yang telah dilakukannya. Allah bukanlah sumber roh jahat, tetapi Allah hanya mengendalikan roh jahat untuk rencana-Nya. Maksudnya bahwa Allah menggunakan roh-roh jahat untuk menjalankan rencanarencana-Nya. Dia memakai roh jahat untuk menghukum Raja Saul dengan gangguan mental yang menjadikan dia seperti gila. Hal ini memberi arti bahwa Allah menggunakan berbagai cara untuk menghukum orang-oarng memberontak kepada-Nya dan untuk menjadikan umatnya lebih baik lagi.11 Roh jahat adalah kuasa yang dapat menguasai atau mempengaruhi seseorang sehingga orang tersebut tidak tenang atau bahkan jatuh sakit. Allah mengisinkan roh jahat menguasai Saul sebagai cara Allah memberikan hukuman dan teguran bagi Saul agar tidak memberontak kepadaTuhan. Tujuan dari penghukuman Allah melalui roh jahat agar Saul menyadari apa yang telah dia perbuatnya.

Allah tidak pernah menolak umat-Nya, dia sangat peduli terhadap umat-Nya. Dia akan memakai segala situasi yang sedang umat-Nya hadapi untuk menjadikan umat-Nya lebih baik. Sekalipun dalam situasi yang buruk Allah akan menerima umat-Nya untuk menggenapi tujuan-Nya menjadikan umat-Nya lebih baik.12 Rencana Allah sangat sulit

8Ibid., 426.

9Ibid.

88.

${ }^{10}$ Limi Halim, New Life: Hidup Baru -40 Hari Transformasi Hidup Menjadi Baru (Visi Press, 2011),

11 Charles C Ryrie, Teologi Dasar 1 Panduan Populer Untuk Memahami Kebenaran Alkitab (Yogyakarta: Andi, 1991), 238.

12 Rick Warren, Jawaban Allah Atas Masalah-Masalah Hidup Yang Sulit (Yayasan Glorya, 2019), 183. 
untuk dipahami, karena Allah memakai segala sesuatu untuk melakukan yang terbai bagi umat-Nya.

\section{Allah Berdaulat Atas Umatnya}

Kedaulatan Allah menjamin bahwa keselamatan manusia hanya bergantung kepada Tuhan. Allah berkehendak agar manusia mengamalkan kemuliaan Allah.13 Allah menghendaki roh jahat mengganggu Saul dalam 1 Samuel 16:14 agar ia sadar dan melakukan apa yang baik bagi Tuhan. Kedaulatan Allah bukan berarti meniadakan kasih Allah. Kedaulatan Allah tidak boleh dipahami terasing dari kasih yang tidak terselami.14 Walaupun Allah memakai roh jahat untuk membuat Saul bertobat, tetapi bukan berarti Allah tidak mengasihi dia. Allah mengasihi dia sehingga Allah turut bekerja dalam permainan kecapi Daud sehingga roh jahat itu undur dari pada Saul.

\section{Kesimpulan}

Setelah melakukan analisa atau kajian terhadap roh jahat yang dari pada Tuhan dalam 1 Samuel 16:14-23, maka dapat disimpulkan bahwa: pertama, Allah bukan sumber roh jahat. Tetapi Allah menghendaki dan mengendalikan roh jahat untuk menjalankan rencana-Nya. Kedua, Allah memakai segala sesuatu untuk rencananya, baik roh jahat maupun yang baik Allah memakainya. Allah tidak dapat dibatasi oleh apapun dan segala sesuatu dapat dipakai oleh-Nya. Salah satu yang dipakai Allah ialah roh jahat untuk menghukum Saul. Ketiga, Allah berdaulat atas umat-Nya. Artinya Ia melakukan segala sesuatu untuk mendatangkan hal yang baik bagi umat-Nya.

\section{Referensi}

Boehlke, Robert Richard. Sejarah Perkembangan Pikiran Dan Praktek Pendidikan Agama Kristen. BPK Gunung mulia, 1997.

Bosch, David J. Transformasi Misi Kristen. BPK Gunung mulia, 1991.

BUSH, W.S LASOR D.A HUBBARD F.W. PENGANTAR PERJANJIAN LAMA 1 TAURAT \& SEJARAH. JAKARTA: Gunung mulia, 2011.

Halim, Limi. New Life: Hidup Baru -40 Hari Transformasi Hidup Menjadi Baru. visi Press, 2011.

PATERSON, ROBERT M. TAFSIR ALKITAB KONTEKSTUAL-OIKUMENIS 1 \& 2 SAMUEL. JAKARTA: BPK Gunung mulia, 2017.

Ryrie, Dr. Charles C. TEOLOGI DASAR 1 PANDUAN POPULER UNTUK MEMAHAMI KEBENARAN ALKITAB. Yogyakarta: ANDI, 1991.

Tsumura, David. The New International Commentary on the Old Testament: The First Book of Samuel. Grand Rapids, MI: Eerdmans Publishing Co, 2007.

Warren, Rick. Jawaban Allah Atas Masalah-Masalah Hidup Yang Sulit. Yayasan Glorya,

13 Robert Richard Boehlke, Sejarah Perkembangan Pikiran Dan Praktek Pendidikan Agama Kristen (Jakarta: BPK. Gunung Mulia, 1997), 27.

14 David J. Bosch, Transformasi Misi Kristen (Jakarta: BPK Gunung Mulia, 1991), 400. 
SOPHIA: Jurnal Teologi dan Pendidikan Kristen, Vol 1, No 1 (Juni, 2020)

2019. 